\title{
RESEARCH OF COMPLEX SILICON-ALUMINUM REDUCTANTS FOR SMELTING VANADIUM MASTER ALLOYS
}

\author{
V. A. Andreyashchenko ${ }^{1}$, Ye. V. Nikurashina ${ }^{1,2}$, A. S. Baisanov ${ }^{2}$ \\ ${ }^{1}$ Karaganda State Technical University, Karaganda, Republic of Kazakhstan \\ ${ }^{2}$ Abishev Chemical-Metallurgical Institute, Karaganda, Republic of Kazakhstan \\ *Corresponding author. E-mail: vi-ta.z@ mail.ru; address for correspondence: 56 Mira blvd, Karaganda, \\ 100027, Kasakhstan. Tel.: +7 7212 564353, fax: +77212564353
}

One of the most pressing challenges facing modern science and technology is creation and industrial implementation of new promising materials and creation of high-quality products from them.

Today marked an increasing demand of steel mills in the ferroalloys of vanadium that raises the question of the development of new technologies for the production of vanadium-containing materials.

At the initial stage of development of technology was conducted a preliminary calculation of the raw materials, aimed at obtaining ligatures of vanadium alumosilicothermic method.

Reactivity of charge components poorly expressed, so we propose a method of bringing the raw materials to the nanostate.

Keywords: ferro-silicon-aluminum, complex silicon-aluminum reductant, vanadium master alloy, nanosize materials.

DOI: $10.17804 / 2410-9908.2016 .2 .006-013$

\section{References}

1. Moskalyk R.R., Alfantazi A.M. Processing of vanadium: a review. Minerals Engineering, 2003, vol. 16, iss. 9, pp. 793-805. DOI: 10.1016/S0892-6875(03)00213-9.

2. Grebnev Yu.V., Dotsenko V.V., Kraeva N.G., Filippenkov A.A., Golub Ye.I., Trop L.A. Reducing the cost of steel castings by alloying of vanadium. Liteynoe proizvodstvo, 2006, no 5, pp. 48-51. (In Russian).

3. Mineral commodity summaries. U.S. Geological Survey, Reston, Virginia, US, 2013.

4. FAN Jin-ping, TAN Zhao, PENG Ke-wu, ZHENG Xi-juan Technological parameters of smelting high vanadium ferrovanadium with mixture of $\mathrm{V}_{2} \mathrm{O}_{5}$ and $\mathrm{V}_{2} \mathrm{O}_{3}$. Journal of Iron and Steel Research, 2013, vol. 25, no. 8, pp. 24-27.

5. Zheng Xi-juan, Peng Ke-wu, Pu Nian-wen, Ma He-li, Shi Hu. Technological parameters of smelting high vanadium ferrovalloy by outside furnace process. Journal of Iron and Steel Research, 2012, vol. 24, no. 9, pp. 6-9.

6. Li Long, Ge Wen Sun, Chen Yong, Sun Zhao Hui. Study on Slag Corrosion of the Magnesia Lining During Ferrovanadium Smelting Process. In: CMTEE 2013: 2013 International Conference on Materials, Transportation and Environmental Engineering, Aug 21-23, 2013, Taichung, Taiwan. Advanced Materials Research, 2013, vol. 779-780, pp. 96-100. DOI: $10.4028 / w w w . s c i e n t i f i c . n e t / A M R .779-780.96$.

7. Li L. Effects of $\mathrm{SiO}_{2}$ and $\mathrm{Al}_{2} \mathrm{O}_{3}$ Contents of Converter Slag on Metallurgical Properties. In: 2012 International Conference on Chemical Engineering, Metallurgical Engineering and Metallic Materials, CMMM, October 12-13, 2012, KunMing, China. Advanced Materials Research, 2012, vol. 581-582, iss. 1, pp. 373-377. DOI: 10.4028/www.scientific.net/AMR.581-582.373.

8. Andreyashchenko V., Nikurashina Ye., Baisanov A. Development of technology of smelting ligatures of vanadium alloys with complex silicon-aluminum reductant. Uspekhi sovremennogo estestvoznaniya, 2015, no. 11, pp. 7-10. (In Russian). 
9. Ospanov N.I., Baisanov A.S., Makhambetov Ye.N., Musin A.M., Omarov M.Sh. Evaluation of the possibility of obtaining ligatures of vanadium alloys, using as a reducing agent siliconaluminum alloys. In: Mezhdunarodnaya nauchno-prakticheskaya konferentsiya "Nauchnotehnicheskiy progress v metallurgii», 2015, pp. 216-218. (In Russian).

10. Naizabekov A.B., Andreyashchenko V.A. Metody intensivnoy plasticheskoy deformatsii dlya polucheniya subultrazernistykh i nanostrukturnykh materialov [Techniques of severe plastic deformation for subultragrained and nanostructured materials]. Rudnyy, RII Publ., 2014, 202 p. (In Russian).

11. Andreyashchenko V. Development and research of a method of intensive plastic deformation for subultragrained and nanostructured materials. Ph.D thesis, Temirtau, 2013, 216 p. (In Russian). 
Подана в журнал: 22.12 .2015

УДК 621.745.55

DOI: $10.17804 / 2410-9908.2016 .2 .006-013$

\title{
ИССЛЕДОВАНИЕ КОМПЛЕКСНЫХ КРЕМНИЙАЛЮМИНИЕВЫХ ВОССТАНОВИТЕЛЕЙ ДЛЯ ВЫПЛАВКИ ВАНАДИЕВЫХ ЛИГАТУР
}

\author{
В. А. Андреященко ${ }^{1 *}$, Е. В. Никурашина ${ }^{1,2}$, А. С. Байсанов ${ }^{2}$ \\ ${ }^{1}$ Карагандинский Государственный Технический Университет, Караганда, Казахстан \\ ${ }^{2}$ Химико-металлургический институт им. Ж. Абишева, Караганда, Казахстан \\ *Ответственный автор. Электронная почта: vi-ta.z@mail.ru; адрес для переписки: 100027, Казахстан, Караганда, \\ Б. Мира 56. Телефон: 8 (7212) 56-43-53, факс: 8 (7212) 56-43-53
}

Одной из наиболее актуальных задач, стоящих перед современной наукой и техникой, является создание и внедрение в промышленность новых перспективных материалов и создание из них высококачественных изделий.

На сегодняшний день отмечается возрастающая потребность сталелитейных заводов в ванадиевых ферросплавах, что ставит вопрос о разработке новых технологий получения ванадийсодержащих материалов.

На начальном этапе разработки технологии был произведен предварительный расчет шихтовых материалов, ориентированный на алюмосиликотермическое получение ванадиевой лигатуры.

Реакционная способность компонентов шихты слабо выраженная, поэтому предложен метод доведения шихтовых материалов до наносостояния.

Ключевые слова: ферросиликоалюминий, комплексный кремнеалюминиевый восстановитель, ванадиевая лигатура, наноразмерные материаль.

\section{1. Введение}

Рост мирового потребления металлов обострил вопрос сырьевого обеспечения металлургической промышленности мира. Возрастающие спрос и цена на ванадий и его сплавы в новых отраслях промышленности и техники требуют все большего количества ванадия и новых технологий его производства. Для обеспечения возрастающей потребности в феррованадии, ведутся исследования по разработке технологий получения различных ванадийсодержащих материалов.

Как известно, в земной коре ванадия намного больше, чем хрома, никеля, свинца, цинка и даже меди. Однако минералы, богатые ванадием, встречаются редко. Соединения ванадия более растворимы, чем природные соединения других металлов, расположенных в правой половине менделеевской таблицы, и перемещаются в горных породах на значительные расстояния. Ванадий накапливается в некоторых рудах других металлов - свинца, меди, цинка, урана, а также в угле, нефти, сланцах.

По распространенности ванадий можно поставить рядом с такими металлами, как никель, медь и цинк. Несмотря на это ванадий до настоящего времени относят к группе редких элементов. Это связано с тем, что может изменять в широком интервале свою валентность. Образуя нерастворимые комплексные соединения с различными металлами, он большей частью находится в железных и полиметаллических рудах. Этим и объясняется его значительная рассеянность в природе [1].

Содержание всего лишь 0,1 \% ванадия может удвоить прочность стали. Это обеспечивает существенную экономию материальных затрат и уменьшение потребления ресурсов горнодобывающего сектора [2-7]. 
Внимание исследователей всего мира привлекают наноструктурные материалы в связи с тем, что их физико-химические свойства существенно отличаются от свойств крупнозернистых объемных материалов. Уменьшение размера кристаллитов ниже некоторой пороговой величины может приводить к значительному изменению фундаментальных характеристик материала (магнитные, механические свойства, диаграммы равновесных состояний вещества и др.).

Перспективность использования наноматериалов в качестве основы конструкционных материалов, обладающих высокими механическими и теплофизическими свойствами, в настоящее время сомнений не вызывает. Наноматериалы представляют собой ансамбли частиц, размеры которых обычно не превышают 100 нм, причем для них характерно уникальное сочетание механических и физических свойств, которые в ряде случаев существенно превосходят свойства массивного состояния тех же материалов.

В настоящее время наноматериалы находят все более широкое применение в получении твердых сплавов, магнитных, сверхпроводящих, полупроводниковых и композиционных материалов. Высокая удельная поверхность и реакционная способность наноматериалов обусловливает возможность их эффективного использования в качестве фильтров, геттеров, катализаторов, а также в качестве добавок, существенно улучшающих эксплуатационные свойства материалов. Наноматериалы могут служить своеобразными модельными объектами для исследования свойств поверхности твердых тел, что представляет большой интерес как для полупроводникового приборостроения, так и для изучения процессов адсорбции и гетерогенного катализа.

Однако ограниченность знаний о свойствах наноматериалов, которые в ряде случаев не укладываются в рамки традиционных физических представлений, снижает эффективность их использования в научных и промышленных целях.

По существующей технологии производство феррованадия складывается из двух процессов: восстановительного и рафинировочного. Шихтовыми материалами для производства феррованадия являются гранулированная пятиокись ванадия, дробленая до 10-30 мм, ФС75, алюминий в гранулах менее 30 мм, стальная стружка и известь.

Существенными недостатками известных способов получения ванадиевых сплавов являются большие трудозатраты, связанные с перефутеровкой тигля после каждой плавки. Также безвозвратные потери ванадия с отвальными шлаками, большие затраты электроэнергии, повышенный расход дорогостоящего алюминия и снижение производительности процесса ввиду проведения дополнительной операции рафинирования, что значительно ухудшает технико-экономические показатели.

Цель настоящей работы заключается в получении наноразмерного восстановителя для увеличения площади реакционной поверхности данного материала.

\section{2. Материал и методика}

В разрабатываемой технологии предлагается при восстановлении оксидов ванадия в производстве ванадиевой лигатуры, вследствие высокой стоимости порошка алюминия и с целью снижения себестоимости выплавки, производить частичную замену кремния ферросилиция (традиционного восстановителя), на более сильный восстановитель, такой как алюминий комплексного кремнеалюминиевого сплава [8].

Схема технологического процесса по предлагаемой технологии:

- $\quad$ загрузка шихты в реакционное пространство блока;

- $\quad$ проплавка;

- $\quad$ остывание с блоком;

- $\quad$ разбор блока;

- отделение шлака от выплавленного металла. 
По результатам химического анализа принято решение применения в качестве восстановителя кремнеалюминиевого сплава с более высоким содержанием алюминия, что предположительно должно увеличить и содержание ванадия в полученном металле. Поэтому при выборе из нескольких комплексных восстановителей выбрали ферросиликоалюминий (ФСА). Для выплавки ванадиевой лигатуры в качестве восстановителя использован кремнеалюминиевый сплав с содержанием элементов 53,03\% Si; 25,8 \% Al; 0,47 \% Ca; 17,88 \% Fe; $1,1 \% \mathrm{Ti}$.

На основании результатов, представленных в работе [9], в качестве шихтовых материалов выбраны пентаоксид ванадия $\left(\mathrm{V}_{2} \mathrm{O}_{5}\right)$, железная стружка, флюсующая добавка в виде оксида извести и ферросиликоалюминий.

Комплексный восстановитель истирали на вибрационной шаровой мельнице типа ММ301. Продолжительность истирания ФСА на мельнице, а также температуру, давление и подбор связующего для прессования, подбирали на основе работ [10-11].

\section{3. Результаты и обсуждение}

Исследование порошка ферросиликоалюминия после измельчения в течение 30 мин на сканирующем электронном микроскопе TESCAN VEGA // LSU показал, что средний размер частиц составляет 120-150 нм, но при этом также наблюдаются частицы, достигающие размера 70-80 мкм (рис. 1). Наблюдаемый разброс размеров частиц требует проведения дальнейшего измельчения.

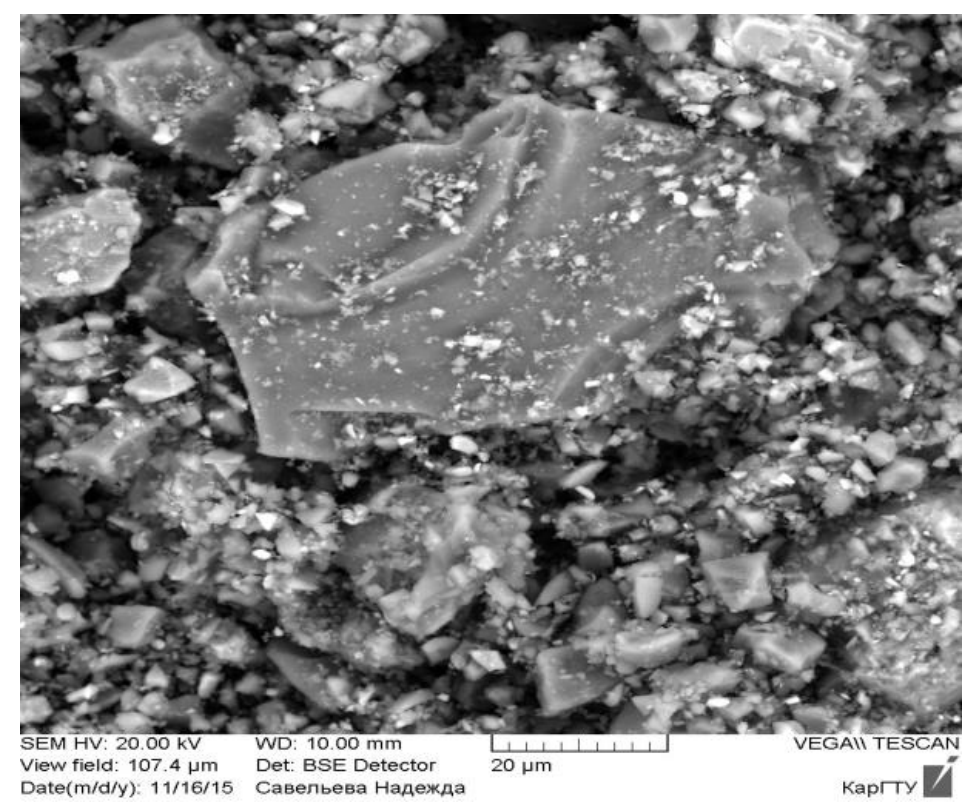

Рис. 1. Фотография порошка ферросиликоалюминия после измельчения в течение 30 мин

Увеличение времени измельчения до 60 мин обеспечило получение более однородного по размерному признаку порошка. Анализ частиц показал, что минимальный размер составляет 37 нм, максимальный - 65 нм. Средний размер частиц $\approx 50$ нм (рис. 2). 


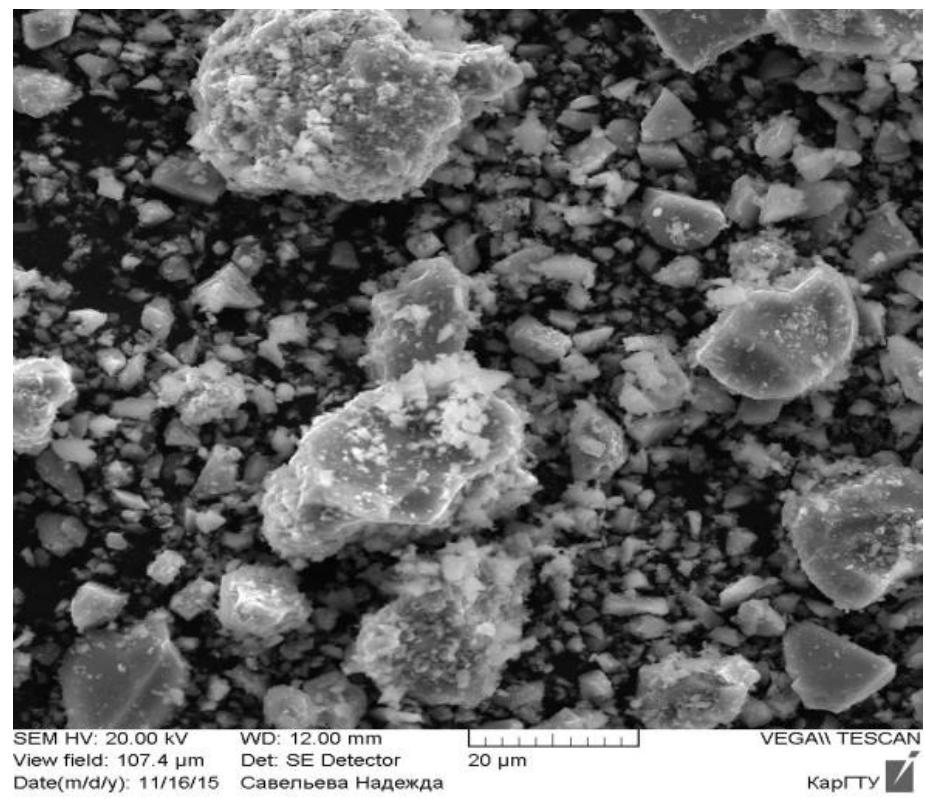

Рис. 2. Фотография порошка ферросиликоалюминия после измельчения в течение 60 мин

Измельчение восстановителя до нанопорошка обеспечит увеличение площади контакта, способствуя тем самым ускорению протекания реакций. При этом высокая дисперсность порошка вызывает усложнение введения его в реакционное пространство тигля, в связи с чем принято решение выполнить компактирование полученного нанопорошка. Для компактирования нанопорошка использован Hydropresse 50. Учитывая хрупкость частиц порошка, о чем также свидетельствует форма частиц после измельчения, компактирование без использования связующего компонента не позволяет получить компакт. С целью получения компактных образцов, пригодных для использования при плавке, в компактируемый материал были добавлены связующие компоненты.

В качестве связующего выбрали термореактивный полимер для горячей запрессовки типа фенольных порошков в пропорции 1:1. Процесс запрессовки вели в двух вариациях: в течении 10 мин и 40 мин при температуре $190{ }^{\circ} \mathrm{C}$ и давлении 270 Бар. Рекомендовано проведение компактирования с выдержкой в течение 40 мин. Однако анализ полученных «таблеток» показал, что после компактирования с выдержкой в течение 10 мин получены качественные компактные образцы. Края компактированных образцов не осыпаются (рис. 3).

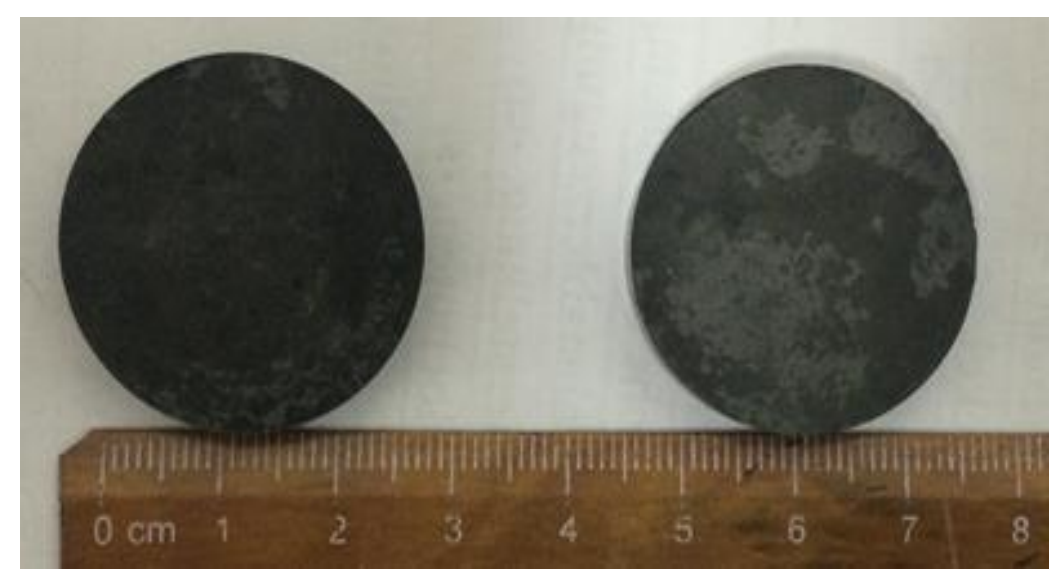

Рис. 3. Вид образцов порошка ферросиликоалюминия после компактирования 
opeth-acegess journal

При нажатии они легко ломаются, что является желательным при использовании в качестве восстановителя. Цвет «таблеток»- черный с характерным блеском пятен фенольной смолы.

Анализ взаимодействия частиц проводили по поверхности излома полученных компактных образцов (рис. 4 и 5). На изломе видно, что частицы имеют осколочную форму, характерную для стекловидных веществ. Это подтверждается химическим составом (содержание кремния $\approx 60 \%$ по массе). Частицы материала не укрупняются и не связываются между собой, так как реакционная способность выражена слабо. Взаимодействие частиц также не наблюдается. Следовательно, проведение компактирования не окажет влияния на реакционную способность полученного нанопорошка восстановителя.

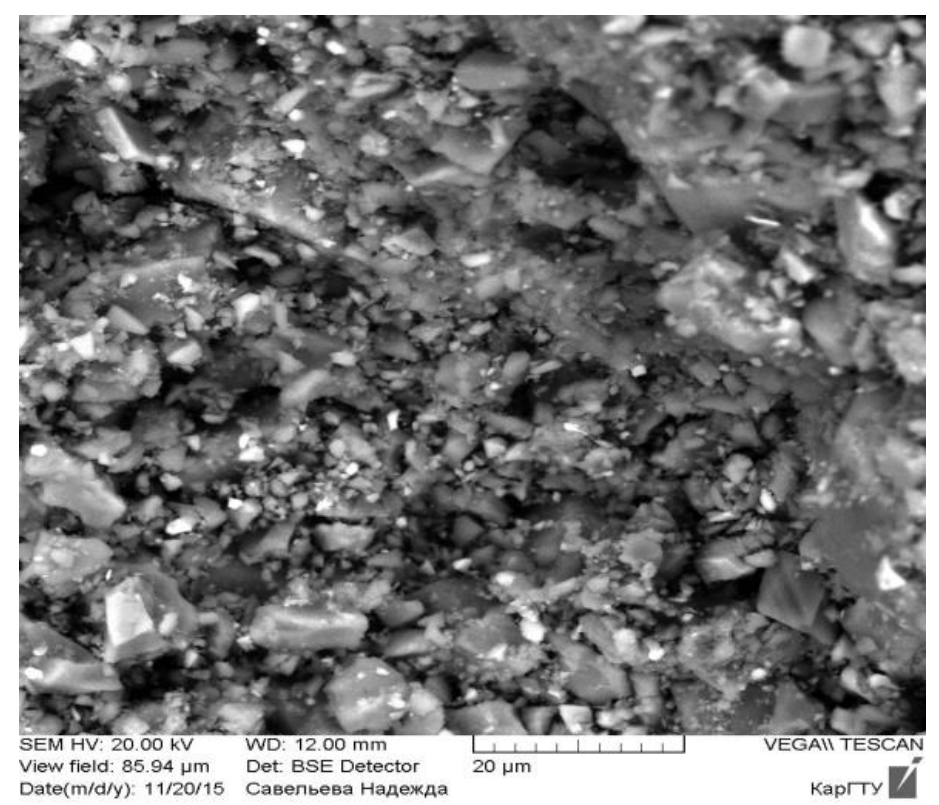

Рис. 4. Порошок ферросиликоалюминия, полученный компактированием. Время компактирования 10 мин

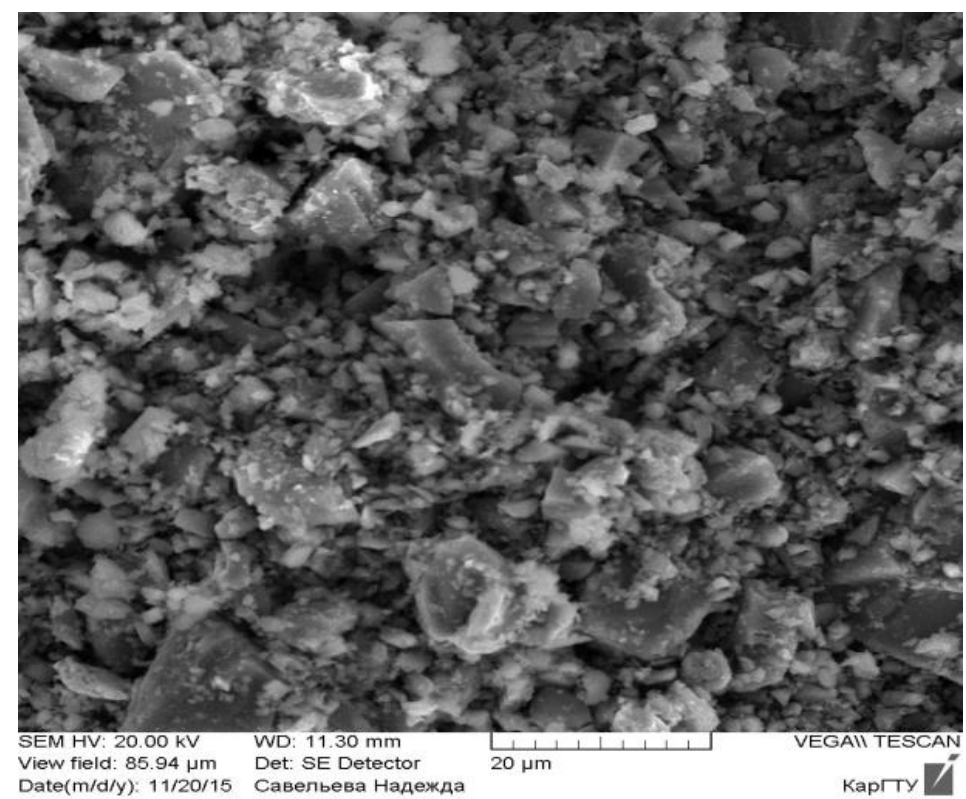

Рис. 5. Порошок ферросиликоалюминия, полученный компактированием. Время компактирования 40 мин 


\section{4. Заключение}

В результате проведенных исследований разработана технологическая схема получения восстановителя для проведения окислительно-восстановительной плавки. Определены параметры процесса получения нанопорошка ферросиликоалюминия. Средний размер частиц порошка ферросиликоалюминия составил $\approx 50$ нм, что соответствует поставленной цели работы. Выявлены параметры компактирования полученных нанопорошков с целью исключения перехода их в улет при плавке. В ходе исследований поверхности компактированных порошков установлено, что взаимодействия частиц, образования новых фаз и укрупнения частиц в результате компактирования не наблюдается.

\section{Литература}

1. Moskalyk R. R., Alfantazi A. M. Processing of vanadium: a review // Minerals Engineering. 2003. - Vol. 16, iss. 9. - P. 793-805. - DOI: 10.1016/S0892-6875(03)00213-9.

2. Снижение себестоимости стальных отливок за счет легирования ванадием / Ю. В. Гребнев, В. В. Доценко, Н. Г. Краева, А. А. Филиппенков, Е. И. Голуб, Л. А. Троп // Литейное производство. - 2006. - № 5. - С. 48-51.

3. Mineral commodity summaries. U.S. Geological Survey. - Reston, Virginia, US, 2013.

4. Technological parameters of smelting high vanadium ferrovanadium with mixture of $\mathrm{V}_{2} \mathrm{O}_{5}$ and $\mathrm{V}_{2} \mathrm{O}_{3}$ / Jin-ping FAN, Zhao TAN, Ke-wu PENG, Xi-juan ZHENG // Journal of Iron and Steel Research. - 2013. - Vol. 25, no. 8. - P. 24-27.

5. Technological parameters of smelting high vanadium ferrovalloy by outside furnace process / Xi-juan Zheng, Ke-wu Peng, Nian-wen Pu, He-li Ma, Hu Shi // Journal of Iron and Steel Research. 2012. - Vol. 24, no. 9. - P. 6-9.

6. Study on Slag Corrosion of the Magnesia Lining During Ferrovanadium Smelting Process / Long Li, Wen Sun Ge, Yong Chen, Zhao Hui Sun // CMTEE 2013: 2013 International Conference on Materials, Transportation and Environmental Engineering, Aug 21-23, 2013, Taichung, Taiwan / Advanced Materials Research. - 2013. - Vol. 779-780. - P. 96-100. DOI: 10.4028/www.scientific.net/AMR.779-780.96.

7. Li L. Effects of $\mathrm{SiO}_{2}$ and $\mathrm{Al}_{2} \mathrm{O}_{3}$ Contents of Converter Slag on Metallurgical Properties // 2012 International Conference on Chemical Engineering, Metallurgical Engineering and Metallic Materials, CMMM, October 12-13, 2012, KunMing, China / Advanced Materials Research. - 2012. Vol. 581-582, iss. 1. - P. 373-377. - DOI: 10.4028/www.scientific.net/AMR.581-582.373.

8. Андреященко В. А., Никурашина Е. В., Байсанов А. С. Разработка технологии выплавки ванадиевой лигатуры с использованием в качестве восстановителя комплексного кремнеалюминиевого ферросплава // Успехи современного естествознания. - 2015. - № 11. C. 7-10.

9. Оценка возможности получения ванадиевой лигатуры с использованием в качестве восстановителя кремнийалюминиевых сплавов / Н. И. Оспанов, А. С. Байсанов, Е. Н. Махамбетов, А. М. Мусин, М. Ш. Омаров // Материалы VIII Международной научно-практической конференции «Научно-технический прогресс в металлургии». - 2015. С. 216-218.

10. Найзабеков А. Б., Андреященко В. А. Методы интенсивной пластической деформации для получения субультразернистых и наноструктурных материалов. - Рудный : РИИ, 2014. - 202 c.

11. Андреященко В. А. Разработка и исследование способа интенсивной пластической деформации для получения субультразернистых и наноструктурных материалов: дис. ... Ph.D. - Темиртау, 2013. - 216 c. 